\title{
Taiwan's "White Paper on Teacher Education": Vision and Strategies
}

\author{
Yi-Huang Shih ${ }^{1, *}$, Shen-Fei Chen ${ }^{2}$, Yan-Hong Ye $^{3}$ \\ ${ }^{1}$ Department of Early Childhood Education and Care, Minghsin University of Science and Technology, Taiwan \\ ${ }^{2}$ Department of Early Childhood Education, Asia University, Taiwan \\ ${ }^{3}$ Teacher Education Center, Ming Chuan University, Taiwan
}

Received July 6, 2020; Revised August 29, 2020; Accepted September 11, 2020

\section{Cite This Paper in the following Citation Styles}

(a): [1] Yi-Huang Shih, Shen-Fei Chen, \& Yan-Hong Ye, "Taiwan's 'White Paper on Teacher Education': Vision and Strategies, " Universal Journal of Educational Research, Vol. 8, No. 11, pp. 5257-5264, 2020. DOI: 10.13189/ujer.2020.081126.

(b): Yi-Huang Shih, Shen-Fei Chen, \& Yan-Hong Ye (2020). Taiwan's "White Paper on Teacher Education": Vision and Strategies. Universal Journal of Educational Research, 8(11), 5257-5264. DOI: 10.13189/ujer.2020.081126.

Copyright $\subseteq 2020$ by authors, all rights reserved. Authors agree that this article remains permanently open access under the terms of the Creative Commons Attribution License 4.0 International License

\begin{abstract}
The implementation of education affects the development and promotion of the country, and a key factor of effective implementation is the cultivation of high-quality teachers. Successful education often depends on teacher quality. This is because teacher professional development is often closely linked with teaching effectiveness as well as the success or failure of student learning. Furthermore, in the discussion of education reform, the quality of teachers is the foundation for the achievement of students and the key to the success of education innovation. In 2012, the Ministry of Education in Taiwan published the "White Paper on Teacher Education". The White Paper promotes teachers' ethics, responsibility, conscientiousness, and sustainability as core values to cultivate teachers with a love for education, professionalism, and effective execution in the new era. It also serves to guide the implementation of teacher education policies. Therefore, the "White Paper on Teacher Education" provides crucial vision and strategies to cultivate teachers in Taiwan. This article analyses the White Paper and supplements the discussion with the relevant literature, aiming to interpret the vision and strategies of "White Paper on Teacher Education". The authors hope to provide clarity regarding teacher education in Taiwan and to offer direction for the future. Alternatively, this article would make a much more in-depth historical excursus of teacher education in Taiwan.
\end{abstract}

Keywords Educational Love, Teacher Education,
White Paper on Teacher Education

\section{Introduction}

Since Japan's formal implementation of teacher education in Taiwan in 1896, the history of teacher education in Taiwan has continued for more than 120 years. Following the teacher education promoted in the era of Japanese governance, the Kuomintang government also implemented teacher education soon after obtaining control of Taiwan, and its teacher education system was a continuation of Mainland China. At that time, the Kuomintang government adopted the anti-communist resistance against Russia and the establishment of national identity as the highest policy, and this policy was used as the basis for Taiwan's education. The failure of Mainland China in the past was largely due to education, and the country's education policy did not practice the Three People's Principles. Therefore, teacher education is necessary so that educators can implement national policies for the Kuomintang government. Furthermore, the system of public funding for normal schools is still maintained (Li, 2001; The Ministry of Education, 1974; Wang, 1978).

Since 1987, the political and social environment in Taiwan has undergone changes, such as the rise of freedom and democratic consciousness. As part of this trend, the teacher education system has also evolved. Because the 
“Teacher Education Law" in 1994, the "Teacher Law" in 1995, and the "Teacher Education Law" in 2002 were successively implemented and promulgated, the teacher education system in Taiwan moved from "single closed" to “multiple opening," and both public funds and financial aid are utilised. After graduating with public funding, students should relocate to schools in remote areas to teach students (Li, 2001; The Ministry of Education, 1974; Wang, 1978).

The "Teacher Education Law" promulgated in 2002 has since been increased from 20 to 26 articles in the current version (Chang, 2002). Teacher education is crucial in Taiwan. In fact, the key to the success of education lies in teachers. The quality of teachers not only affects the competitiveness of the country but also determines the effectiveness of the education system. In recent years, countries have defined the quality of teachers by using the concept of management and used various planning methods (e.g. execution, evaluation, and effective use of resources) to achieve their goals. To improve the quality of teachers, carefully considered strategies should be used to monitor the process of teacher education (including the pre-service stage, introduction stage, and in-service stage) so that teacher quality and teacher education are closely related. To improve the quality of teachers, high-quality teacher education is essential (Liang, 2020).

The Ministry of Education in Taiwan published the "White Paper on Teacher Education" in 2012. The White Paper promotes "teachers' ethics, responsibility, conscientiousness, and sustainability" as core values to cultivate teachers with a passion for education, professionalism, and effective execution in the new era and serves as guidance for the implementation of teacher education policies within the decade (Lin, 2019). This article examines how the "White Paper on Teacher Education" may offer valuable vision and strategies to cultivate teachers in Taiwan. This article analyses the "White Paper on Teacher Education" and then supplements the discussion with the relevant literature to interpret the vision and strategies contained in the "White Paper on Teacher Education”. The authors hope to provide a more comprehensive understanding of teacher education in Taiwan and offer direction for its practice in the future.

\section{The Importance of Teacher Education in Taiwan}

Education is a process that must be taken by every human being in order to be able to live a good and quality life in the world. Quality human resources can be built from educators through superior prophetic educators. Excellent teachers can lead students to excel too. Therefore, qualified teachers are needed to realize these expectations (Hardiyanto, 2020).

The implementation of education affects the development and promotion of the country, and a key factor of effective implementation is the cultivation of high-quality teachers. The professional qualities of teachers are closely related to changes in the domestic social environment, the reform and promotion of education policies, and the development of international trends. Teachers are responsible for fostering future talent, which involves the cognitive ability, skills, and attitudes of developing learners. Furthermore, the job of a teacher is focused on people, including children, adolescents, and adults, and teachers often participate in their development. If the teacher's professional ability is insufficient, students will fail to learn. According to this view, enhancing the professional development of teachers is crucial to educational practice, and teacher education is the primary strategy to do so. Hence, we can understand the value and importance of teacher education in Taiwan (Freire, 1998; Lin \& Hsieh, 2020).

In addition, "The key to the future of the country lies in education; the quality of education is based on teachers". The quality of teachers is the foundation for the achievement of students and the key to the success of education innovation. In the era of globalisation, technology, and lifelong learning, teachers must respond to the continuous changes of society and practice educational love between teachers and students. In addition, teachers should exercise educational professionalism, international perspectives, and critical thinking to form creative, cooperative, and practical teams. Teams of teachers may encourage students to become good citizens with healthy personalities, civic literacy, and lifelong learning ability who can meet the challenges of a globalised world (The Ministry of Education, 2012). To help each child cultivate his or her talents with both humanity and professional competence, teachers are an important influence. Teachers' words and behaviour have profound effects on the students and their learning. Therefore, teacher education is the core of educational quality. Teacher education is important in Taiwan (Chiang, 2012). For this reason, this article focuses on teacher education in Taiwan.

\section{The Development of Taiwan's "White Paper on Teacher Education"}

Faced with drastic changes and challenges in the teacher education environment, the Ministry of Education tasked the Teacher Education Society of the Republic of China in 2004 with ensuring the cultivation of teachers with "professionalism" and "quality", employing strategies such as teacher development, education internships, qualification appraisal, teacher selection, and ongoing professional development of teachers. To develop goal-oriented action plans, the Teacher Education Society put forward the "Proposal on Teacher Education Policy". Based on this proposal, the Ministry of Education announced the "Improvement Program on Teacher Education Quality” on February 23, 2006 to promote the 
reform of teacher education. Three years later, in view of changes in the teacher education environment, the Ministry of Education renewed the "Improvement Program for Primary and Secondary School Teachers” on September 9, 2009. Later, on August 28 and 29, 2010, the 8th National Education Conference took place with "Teacher Education and Professional Development” as the central topic, and it was proposed to release "White Paper on Teacher Education". To implement the recommendations of the National Education Conference and in response to the establishment of the "Department of Teacher and Art Education" by the Ministry of Education and to develop the role of good teachers to lead social progress, the Ministry of Education held the "White Paper Conference on Teacher Education” in October 2010 and formed a working group and steering committee to develop the "White Paper on Teacher Education in the Republic of China” (hereinafter referred to as the "White Paper on Teacher Education"). The meaningful changes in the "White Paper on Teacher Education" are as follows (The Ministry of Education, 2012; Yang, 2015):

1. The orientation of teacher education is not only the pre-service education of teachers but also the professional development of in-service teachers.

2. The scope of teacher education is not only to educate teachers but also to include related professional support systems.

3. The educational institution for teacher education is not only a teacher education university but also includes educational networks of elementary and middle schools and preschools.

4. The purpose of teacher education is not only to provide educational credits but also to help pre-service teachers to develop their moral character and strengthen their teaching ability.

5. The object of teacher education is not only primary and secondary school teachers but also university teachers and education-related professionals such as school administrators and after-school care personnel.

6. The perspective of teacher education is not a one-sided concern but should be planned in a systematic and integrated way.

The "White Paper on Teacher Education" is based on the vision of "cultivating good teachers in the new era to develop global high-quality education”, using “Teachers' Ethics, Responsibility, Conscientiousness, and Sustainability” as core values. By analysing social changes, international trends, current relevant policies, and problems and challenges facing teacher education, the White Paper provides the national development blueprint for the Golden Decade announced by the President. It constructs the ideal image, vision, and goal of teacher education, supplemented by comprehensive planning of "teacher pre-service education", "teacher introduction guidance”, “teacher professional development”, and "teacher education support system”, divided into four aspects, nine development strategies, and 28 action plans. By planning high-quality, conscientious teacher education, this blueprint is designed to create a bright future for teacher education (The Ministry of Education, 2012; Yang, 2015).

\section{Taiwan's Vision for Teacher Education}

\subsection{Ideal Image}

Education is the foundation of a nation and the driving force behind social progress and development. It is an important cornerstone to boost national competition. Taiwan has achieved tremendous economic growth and gained recognition as one of the Four Asian Dragons. One influential factor of this success is Taiwan's excellent human resources (Chiang, 2012). The cultivation of excellent human resources depends on professional teachers. Teaching is a profession that is particularly valued in Taiwanese society and culture because it involves working with children and adolescents who are still developing. The main task of teachers is to help students to develop their potential, achieve self-realisation, and fulfil their social responsibilities in the future (The Ministry of Education, 2012).

Although society is changing rapidly and the public may have varying opinions on the status and image of teachers, the social and cultural respect for teachers' status, responsibilities, and roles remain unaffected by the passage of time in Taiwan. At present, the "Labour Union Law" has been amended and promulgated. Teachers can organise labour unions. However, the public still expects teachers to be professionals, not laborers. Furthermore, according to international trends and domestic social values, teachers should fulfil a "professional" image and contribute to the cultivation of national talents. Due to the changing connotation of human resources in the new era, education urgently needs to think about new ways of teaching in the light of new social trends and changes in student learning culture in Taiwan. Simultaneously, teachers must analyse the new needs of education to form an ideal teacher's image in the new era. In the following section, we clarify the image and core connotation of teachers in the new era as the ideal goal and connotation of teacher education according to the guidance specified in the White Paper (The Ministry of Education, 2012).

\subsection{Teacher Image and Core Values in the New Era}

Teachers who demonstrate a passion for education, professionalism, and executive abilities in the new age are equipped to take care of students and observe their needs, respond to social changes, and face different challenges with enthusiasm for education. In addition, in the face of a diverse social and educational environment, teachers must 
possess critical thinking abilities and a deep understanding of relationships among education, politics, economics, and society. In collaboration with teachers, school education facilitates the mission of teaching, assists in the development of the potential of each student, and promotes students with critical abilities and attitudes, and each student has the opportunity for self-actualisation. Based on this image of a teacher, caring for students is the starting point of a passion for education. Then, teachers must use insight to understand students' development and social changes so that they may continue to educate students with compassion. In the teaching profession, knowledge of subject matter and teaching can be based on critical thinking to develop students' thinking abilities. Furthermore, teachers must understand global development from an international perspective and use problem solving to face the challenges of education and meet requirements to become a professional teacher in the new era (The Ministry of Education, 2012).

Teachers must be able to cooperate with their peers and relevant school education professionals to promote education and then use practical wisdom to innovative education practices. Innovation transforms creative thinking and has a new education role, which is valuable to a competent teacher. Based on this, the teacher has nine core qualities: compassion, insight, enthusiasm, critical thinking, international perspective, problem solving, cooperation, practical wisdom, and innovative ability (The Ministry of Education, 2012). These are illustrated in Table 1.

Table 1. Teacher Image and Its Core Qualities

\begin{tabular}{|c|c|c|c|}
\hline \multicolumn{2}{|c|}{ Teacher Image } & \multicolumn{2}{c|}{ Core Qualities } \\
\hline $\begin{array}{c}\text { teachers with a } \\
\text { passion for } \\
\text { education }\end{array}$ & Insight & care & passion \\
\hline $\begin{array}{c}\text { teachers with } \\
\text { professionalism }\end{array}$ & $\begin{array}{c}\text { international } \\
\text { perspective }\end{array}$ & $\begin{array}{c}\text { Critical } \\
\text { thinking }\end{array}$ & $\begin{array}{c}\text { problem } \\
\text { solving }\end{array}$ \\
\hline $\begin{array}{c}\text { teachers with } \\
\text { execution }\end{array}$ & Innovation & cooperation & $\begin{array}{c}\text { Practical } \\
\text { wisdom }\end{array}$ \\
\hline
\end{tabular}

\subsection{Core Value: "Teachers' Ethics, Responsibility, Conscientiousness, Sustainability"}

In addition to the qualities of passion for education, professionalism, and executive abilities, the cultivation of teachers should emphasise the following four core values to realise the vision of teacher education and develop high-quality education (The Ministry of Education 2012).

1. Teachers' ethics: each teacher plays an exemplary role in society.

2. Responsibility: each teacher guides each student effectively.

3. Conscientiousness: each teacher is working hard to improve the quality of education.
4. Sustainability: each teacher is passionate about the inheritance of culture.

\subsection{Goals}

\subsubsection{Achieving the Teacher's Mission}

In a democratic and pluralistic society undergoing social changes, the Ministry of Education insists that professional teachers strive for excellence in teaching, foster a sense of social justice, and care for all students in a comprehensive manner (The Ministry of Education, 2012).

\subsubsection{Teacher Education Based on Professional Standards}

To provide opportunities for lifelong professional learning, the Ministry of Education encourages the establishment of professional standards-based teacher education and promotes pre-service teacher education to ensure the professional ability of teachers and maintain each student's right to learn (The Ministry of Education, 2012).

\subsubsection{Constructing a Policy Network of Teacher Education and Appointment}

The Ministry of Education aims to construct a policy network of teacher education and appointment that integrates educational administration, political institutions, universities for teacher education, primary and secondary schools and preschools, and educational professional organisations (The Ministry of Education, 2012).

Through this policy network, a professional growth system of pre-service teacher education, guidance, and professional development may improve the quality of education research, and the function of local education guidance should be emphasised to enhance the quality of education (The Ministry of Education, 2012).

\subsubsection{Shaping the Campus Culture of Teachers' Lifelong Learning}

The image of high-quality teachers is established through the systematic in-service teacher education system in a new era and provides a learning support system to stimulate teachers' professional development (The Ministry of Education, 2012).

Lifelong learning helps teachers to respond to rapid changes in society, strengthen critical thinking, consider diverse social perspectives, and expand international horizons to meet global challenges through practical, research-based educational wisdom. Finally, the Ministry of Education encourages forming cooperative teams of teachers, innovative education activities, sustainable development of school culture, and shaping the campus culture of teachers' lifelong learning (The Ministry of Education, 2012). 


\section{Strategies for Teacher Education in Taiwan}

\subsection{Strengthen the Selection and Cultivation of Excellent Talent to Ensure High-Quality Professional Teachers}

The public has high expectations for teacher education policy and the cultivation of high-quality teachers. Therefore, the first priority is to ensure that teachers trained by universities are of high quality, with passion and enthusiasm for education as well as professional qualities and energy for professional growth. To achieve this goal, the teacher education policy must start by strengthening the selection of teachers and encouraging excellent students to choose educational courses for pre-service teachers that improve moral education (The Ministry of Education, 2012).

\subsection{Cultivate Specific Teachers to Respond to National and Social Needs}

The recent trend of globalisation has had a major impact on development in Taiwan. The international transnational population, dynamic immigration, and marriage immigration are increasing rapidly, and the number of marriages to Chinese nationals and citizens of other Southeast Asian countries is also increasing, resulting in numerous new immigrants who have educational needs. Additionally, China's influence on the world has greatly increased, leading to an upsurge in learning Chinese in the world and increasing demand for Chinese language teachers. The teacher education policy should respond to the rapid development of society when cultivating new teachers. In addition to publicly funded students, social development has prompted a need for teachers with diverse backgrounds and areas of expertise, including indigenous teachers, new immigrant teachers, overseas Taiwanese school teachers, overseas Chinese school teachers, Chinese language teachers, and Taiwanese school teachers in Mainland China; Therefore, the teacher education policy must aim to cultivate specific teachers to respond to national and social needs (The Ministry of Education, 2012).

\subsection{Improve the Internship System to Implement Education and Appointment of Pre-service Teachers}

The current internship system stipulates that pre-service teachers have completed the required credits and grades, and it is used as a screening tool for entering the school system. However, the system offers no specific inspection mechanism for pre-service teachers to meet the qualifications and conditions of the school site. Moreover, after education and internship stages, the system offers no specific inspection mechanism for the professional performance of pre-service teachers. For this reason, based on the professional principle of the internship qualification verification mechanism, it is necessary to develop a screening mechanism at this stage and adjust education internship courses to accurately grasp internship students' real professional abilities. In this way, the internship system may improve the implementation of education and appointments for pre-service teachers (The Ministry of Education, 2012). In order to accurately grasp internship students' real professional abilities, Shih (2017) explored what we should cultivate the core competencies of pre-service teachers from the field of contemporary education in Taiwan. In this way, teachers can promote their core competencies to cope with social change, and keep up with the times. Further, after exploring, this study found the core competencies of pre-service teachers are as follows: (1) the ability to practice educational love, (2) the ability to develop a good teacher-student relationship, (3) the ability to practice character education, (4) the ability to counsel students to express emotions, (5) the ability to practice adaptive education, (6) the ability to use instructional technology, (7) the ability of parent-teacher communication, (8) the ability to develop parent-child interactive courses, (9) team work ability, (10) remedial instruction ability, and (11) the ability to use community resources.

\subsection{Assist New and Rural Teachers and Improve the Working Environment}

In each school, new teachers hold an official teaching position within three years. During this time, a teaching tutor provides guidance to beginning teachers and an environment in which new teachers may ask questions regarding the curriculum and teaching. To evaluate the teaching achievements of beginning teachers and protect students' rights, each new teacher's first two years should be entered into a summative evaluation of curriculum and teaching, class management and guidance, and teacher training and research. This evaluation is to ensure that the performance of beginning teachers meets the expectations of the school, students, and parents. To improve the quality of teachers in rural areas, the law should revise the appointment of teachers to meet the actual needs of schools in rural areas to enrich school teachers and reduce their teaching load. Additionally, to coordinate the characteristics of schools in rural areas, the system should continue to implement co-employment in rural areas and support the teaching and living conditions of school teachers in rural areas to retain high-quality teachers (The Ministry of Education 2012). In this way, the working environment may be improved for new and rural teachers. Some studies are to explore the "government-funded system" of the teacher education in Taiwan; this system continues to exist after the diverse teacher education, its 
functions of attracting excellent pre-service teachers and providing excellent teachers required by schools in rural areas (Huang, 2019; Li, Kao, \& Liao, 2016).

\subsection{Construct Systematic Practice-based In-service Education for Teachers}

To meet the needs of teacher professional development, the Ministry of Education has actively strengthened the legal system, implementation and promotion models, organisational operations, financial support, incentive methods, administrative support, evaluation and feedback, and other corresponding measures to achieve the goal of constructing a systematic, practice-based in-service education program for teachers (The Ministry of Education 2012).

\subsection{Stimulate Professional Development and Promote Teacher Evaluation Systems}

In 2006, Taiwan's Ministry of Education began conducting the Teacher Professional Development Assessment to promote the professional growth of primary and secondary school teachers and enhance student learning outcomes. In 2017, it was transformed into the Teacher Professional Development Support System. Specific strategies include teacher professional growth, initial teacher training and the establishment of a network supporting the professional growth and training certification of teaching professionals (Ministry of Education, 2017). The professional development of teachers is the key to the development of education, but to effectively promote professional development, a system to stimulate and supervise growth is required. In view of the educational reality, the majority of primary and secondary school teachers are high-quality employees who are willing to promote their professional knowledge, but inevitably, a small number of teachers are not motivated to do so. For teachers who are willing to grow sustainably, the system should provide a channel for career development. For teachers who exhibit limited growth, the system should urge them to progress or provide an exit through appropriate mechanisms. The establishment of a teacher professional development system is a crucial part of teacher professional development (The Ministry of Education, 2012). Therefore, we should motivate professional teachers through a teacher evaluation system.

\subsection{Integrate Organisation and Information to Innovate the Administration of Teacher Education}

At present, although the overall policy planning of teacher education is managed by the Department of Secondary Education, some businesses are still involved in the Department of Higher Education, Technology and Vocational Education, Education Research Committee, Special Education Working Group, and other groups related to education. The decentralisation of business has resulted in overlapping powers that require clarification. Communication and coordination are time consuming, and the organisational operation does not perform efficiently. To improve this situation, the Ministry of Education established the Department of Teacher Education and Art Education, which integrates all policies and related business to strengthen the operation, planning, and execution of teacher education (The Ministry of Education, 2012).

\subsection{Support the Universities of Teacher Education to Augment the Function of Teacher Education}

The Ministry of Education supports basic conditions for universities to execute teacher education including developing a curriculum and support mechanisms for teacher educational programs and encouraging university teachers to form professional learning communities to promote professional development through dialogue and cooperation. In response to changes in social trends, universities must cultivate cultural and educational industry personnel through the establishment of departments or courses. Additionally, recognition and evaluation should be used to reward performance and maintain the high quality of teachers. In this way, we can support the universities of teacher education to improve the function of teacher education (The Ministry of Education, 2012).

\subsection{Build an Education Personnel System to Improve the Quality of School Education}

In a lifelong learning society, an individual in any profession must continue lifelong learning to promote professional knowledge. This is especially true for educators because they have the responsibility of teaching and nurturing the next generation. Therefore, we must strengthen the educational profession to align with the goal of building a lifelong learning society. In the future, existing regulations and resources must be reviewed and integrated to plan the core competence for teaching positions and diversified professional development courses. The development needs of educational personnel should be assessed, and professional courses that meet the needs of further education should be planed. At the same time, it is necessary to establish a professional growth mechanism and license system for education and school officials to ensure their professional status and to support high-quality teachers to implement educational work by building an education personnel system to improve the quality of school education (The Ministry of Education, 2012).

\section{Conclusions}

Education is widely regarded as an extremely 
meaningful endeavour that promotes the holistic development of students. It is also regarded as a tool for maintaining social harmony and the transfer of cultural values between human generations. Therefore, human beings typically develop as individuals through educational activities (Brezinka, 1992). Teachers play a critical role in this educational process. In addition, teachers provide a professional service for the public good: they generate the intangible public good of schooling; not because the service is funded by the public, but rather because it serves the public to improve the student's life (Werler, 2015).

In 1983, the US Department of Education published a report on "A Nation At Risk". The report bluntly stated that education in the United States is low in quality, and without improvement, the United States could lose its position as a leading global power. The report also proposed numerous improvement programs, including "improving the teacher education system and improving the quality of teachers". This report also states that high-quality teachers are a basic condition for educational reform (Shih, 2003). In 2012, the Ministry of Education in Taiwan published the "White Paper on Teacher Education”. The White Paper promotes "teachers' ethics, responsibility, conscientiousness, and sustainability" as core values to cultivate teachers with a passion for education, professionalism, and effective execution in the new era. It also serves as guidance for the implementation of teacher education policies (Lin, 2019).

This article examines how this document constructs the overall image of teacher education and serves as the basis for teacher education policy to cultivate excellent teachers in Taiwan in the 21st century (The Ministry of Education, 2012). To achieve the teacher's ideal image, education authorities and schools should establish a teacher support system, including sound administrative support, sufficient teaching resources and equipment, sufficient school personnel allocation, and a sound social support network, combined with administrative staff, counsellors, social organisations, and medical institutions to assist teachers in effectively teaching and achieving educational goals (The Ministry of Education, 2012).

The strategies are as follows: (1) strengthen the selection and cultivation of talent to ensure high-quality professional teachers, (2) cultivate specific teachers to respond to national and social needs, (3) improve the internship system to implement education and appointment of pre-service teachers, (4) assist new and rural teachers and improve the working environment, (5) construct systematic and practice-based in-service education for teachers, (6) stimulate professional development and promote teacher evaluation systems, (7) integrate organisation and information to innovate the administration of teacher education, (8) support the universities of teacher education to augment the function of teacher education, and (9) build an education personnel system to improve the quality of school education.

Finally, the authors hope that such a discussion can help people understand the vision and strategies of teacher education in Taiwan and provide direction for teacher education so that teacher education in Taiwan may improve. When students benefit from teachers' lessons, the society and country of Taiwan benefit in turn.

\section{REFERENCES}

[1] Brezinka, W. (1992). Philosophy of educational knowledge: An introduction to the foundations of science of education, philosophy of education and practical pedagogics (J. S. Brice \& R. Eshelman trans). London, UK: Kluwer Academic Publishers.

[2] Chang, Y. C. (2002). Analysis of the newly issued "Teacher Education " (Part 2). National Education, 43(1), 2-6.

[3] Chiang, W. N. (2012). Preface. In The Ministry of Education (Ed), White paper on teacher education (pp. 1-2). Taipei City: The Ministry of Education.

[4] Hardiyanto, F. E. (2020). Revitalizing the prophetic teacher ethic in developing human resources for education. Universal Journal of Educational Research, 8(6), 2686-2692.

[5] Huang, J. L. (2019). A Historical Approach on the Government-Funded System for Teacher Preparation. Journal of research in education sciences, 64(2), 99-129.

[6] Li, C. W., Kao, C. M., \& Liao, Y. W. (2016). A review of plan b's selection system of tuition-free scholarship funded by the government for student teachers. Bulletin of Research on Elementary Education, 34, 1-30.

[7] Li, Y. H. (2001). History of teacher education in Taiwan. Taipei City: National Institute for Compilation and Translation.

[8] Liang, F. (2020). Practice and enlightenment of quality assurance mechanism of German teachers' education. Taiwan Education Review Monthly, 9(5), 16-23.

[9] Lin, C. C., \& Hsieh, C. L. (2020). The current teacher education in secondary schools: Challenges and response. Taiwan Education Review Monthly, 9(5), 9-15.

[10] Lin, J. Y. (2019). Reflections on the pre-service teacher education and the teacher professional development after the publication of the teacher education white paper. Journal of Educational Research and Development, 15(1), $1-28$.

[11] Shih, Y. H. (2003). Retrospect and prospect: A historical reflection on teacher education in the age of knowledge economy. Journal of Elementary Education, 15, 232-251.

[12] Shih, Y. H. (2017). A study on exploring what we should cultivate the core competencies of pre-service teachers from the field of contemporary education in Taiwan. Chang Gung Journal of Sciences, 26, 73-88.

[13] The Ministry of Education (1974).The fourth Republic of China education yearbook. Taipei City: Cheng Chung

[14] The Ministry of Education (2012). White paper on teacher 
education. Taipei City: The Ministry of Education.

[15] Ministry of Education (2017). The Ministry of Education subsidizes the main points of the professional development practice plan for teachers. Taipei City: Author.

[16] Wang, Z. T. (1978). Newly edited educational materials in Taiwan. Taipei City: The Commercial Press.
[17] Werler, T. (2015). Commodification of teacher professionalism. Policy Futures in Education, 14 (1), 60-76.

[18] Yang, S. W. (2015). The policy background of teacher education. In S. W. Yang (Ed), A comment on white paper on teacher education (pp. 2-16). Taipei City: Psychology. 